\title{
Study on the Current Situation and Trend for the Application of "3S" Technology in Land Resource Management
}

\author{
Gou Xiaojiang \\ School of Management in Xizang Minzu University Xianyang, Shaanxi 712082 \\ 59624917@163.com
}

\begin{abstract}
Keywords: 3S; Land resource management; Dynamic monitoring; Resource planning; Land Renewal Investigation; Data
\end{abstract}

\begin{abstract}
As the development of land resources vary from time to time, the accuracy and strength of efficiency for relevant work is doomed to be affected if the function of real-time dynamic information investigation is neglected in the technology of land resource management. As a result, rational coordination, planning, utilization and protection of land resources would fail to function. As the pilot technology in automatic intelligent domain of the information age, the function of $3 S$ technology is strong in comprehensiveness and obvious in excellence, which is prospective in the management of land resources. Based on $3 S$ technology, this paper analyses the practical application process of this technology in the management of land resources from multi angles, and makes proper prospect for the development of this technology in the field of land resources management in the future.
\end{abstract}

Land is the source of wealth for human beings and China is abundant in land resource as it has vast territory and abundant resources. However, not mature enough technology on national land resources management weakens the effectiveness of land planning and future decision in our country, which is the bottleneck for the evolution of national land forces. The introduction of 3S technology can fill up the lack of data information in land resources, so as to update the real data on land resource utilization and provide the future planning and utilization of national land with more effective technical support.

\section{S Technology}

The basic concepts of 3S Technology. So-called 3S technology is composed of three techniques, including the technology of GPS--Geographical Information System, RS--Remote Sensing, and GIS--Geographical Information System. In a narrow sense, they are defined as geographic information technologies while they are called the core of geographic information technology in a broad sense. The three kinds of technologies together complete the tasks of spatial information location, storage management, analysis, application and updating for the objects observed and they are strong in the ability of comprehensive management and integrated processing. At the same time, under the influence of its intelligence, dynamic storage of data is also possible, which highly improve the accuracy of work data on land resources management.

Generally speaking, the 3S technology plays an individual, comprehensive and integrative role in the application process of land resource management, which enables the traditional mode of land resources management gradually change into the integrated and diversified model. For example, the high resolution of RS, whose image interpretation includes visual inspection-- human interaction-automatic extraction of information, lead to more and more diverse and dynamic land resources management and wholly new distributed management system on land resources.

The basic characteristics of 3S Technology. The science of land resource management is based on the following five characteristics of 3S technology: positioning, qualitative, quantitative, timing and fixed spectrum.

The first characteristic is positioning. All the three technologies of 3S technology can achieve accurate positioning for the management of land resources, and they also guarantee the accuracy of the mutual relations for the locations of land divisions, and ensure the right theories in geographical 
analysis and accurate judgment for information. However, the most important part of the positioning work is mainly completed by GPS.

The second is qualitative, which makes classification for the information obtained. That is, it makes different limited qualitative for different objects. The qualitative of land resource management is mainly completed by RS.

As for land resource management, quantitative means quantitative assessment for land area, arable land area, crop yield assessment and urban greening rate etc. After completing affirmed quantitative assessment for this information, work for land resource management can be further done.

Timing, the real time technology applied in the technology of 3S land resource management transplanted from science and technology in other field, meets all the needs of land resource management, such as the technology of GIS and RS. In general, the remote sensing information involved in the timing technology is transmitted by the remote sensing satellite, and the timing technology is for specific phase.

The last is the technology of fixed spectrum. Remote sensing image exist in a variety of channels for remote sensing spectrum and the characteristics of fixed spectrum for RS is reflected in processing the information for electromagnetic radiation of ground object received, which improves the accuracy of the data in the management of land resources to certain degree.[1]

\section{Application status of 35 technology in the management of land resources}

In view of the present situation, 3S technology is widely applied in the field of land resource management and tends to develop toward the direction of comprehensive and integrated application. It not only permeates to every aspects of land resources management, but also greatly promotes the scientific decision-making of land resources management and modern management level.

The design and application of land renewal investigation that has been integrated into $3 S$ Technology. Land renewal investigation, also called investigation on the updating of land use, means making detailed investigation for land data and image modification for land resources based on existed results. The purpose of making updated investigation for land data and making contrast and analysis on the modification of investigated data can be finally achieved under the help of RS that can express the current data and information by making detailed analysis on the land data according to the scale in investigation.

(1)The management mode combining files with relational database. The mode combining files with relational database is called mixed management, which manages the spatial data with GIS software. Its advantage lies in making full use of relational database to support the system with strong attribute data management. When the ability of attribute data management rises, construction ability of land resources database will be greatly improved. In this process, the analysis of GIS and management functions of spatial data will be greatly embodied.

(2)Management mode of object-oriented spatial database. Management mode of object-oriented spatial database can liberate the limitation of the spatial data in the relational database and GIS spatial data can be managed by establishing object database. These data are composed of the geometry such as point, line and surface etc and they contains the mathematical operation such as copulating distance and spatial relationship for land. Moreover, they establish buffer area and model of stackup analysis for land renewal investigation, so as to realize seamless connection for information in the database management system and simplify such analysis process. As shown in Figure 1 


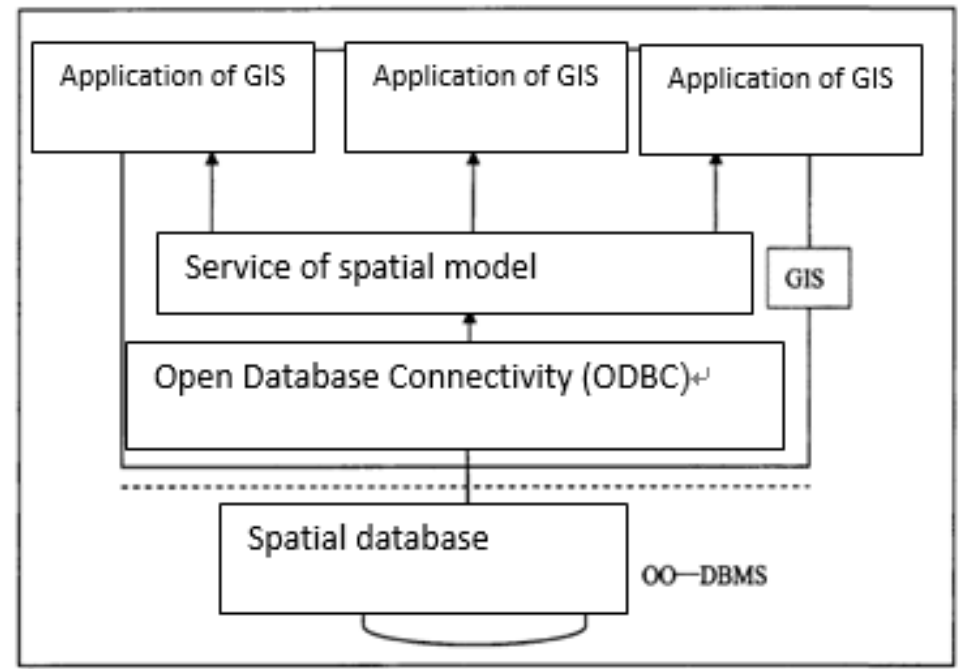

Fig. 1 Schematic diagram management mode of database for land resources based on objectoriented space

As shown in Figure 1, database for land resources based on object-oriented space supplies the management work with electronic access interface for unified data and partial models for spatial service. These settings increase the ability of data sharing and realize the global sharing for spatial model service. In this system, GIS software is mainly used in the data model, which reflects the complexity and openness of data, so that the object database system will be more mature in management.

Analysis of the application status for other technologies. 1). Investigation on land resources. Remote Sensing (RS) technology based on aerospace can directly or indirectly conduct Digital Photogrammetric Technology Survey and Mapping for field land, transform the collected data into GIS platform for digital processing, and eventually enter the background management warehouse. Its unconventional approach for mapping is done with 3S technology as reference--with image data of GS as frame of reference, GPS as data source and GIS as a platform to carry out the map spot drawing, and then complete the resource investigation and processing. Compared with the traditional investigation approaches on land resource, this approach has been improved in terms of accuracy and efficiency, and this technique is employed in the dynamic investigation of land resources in the northwest of China. Taking Shaanxi Province as an example, we'd firstly design classification system for land resources investigation and carry out the following three processes based on data obtained by GS remote sensing: image interpretation for human-computer interaction -- vector graph editing - digitization of the data obtained from GIS. By employing 3S technology, Shaanxi province changed the work flow on land change investigation and obtained more accurate spatial location in the changed map spot. For example, the technology of WebGIS can be employed in the detailed information system of B / S mode in the town, county and city level of Shaanxi Province. Thus, the dynamic investigation and management on data can be realized so as to achieve the goal of land data investigation.

2). Land resource planning. Because of the vast territory of our country, we will inevitably experience a variety of disasters, including desertification, drought, soil erosion, environmental pollution and so on. Thus, land resource planning is of vital importance. The application of land resource planning based on 3S technology can be used to restore the productivity of land resources. For example, in the downstream of the Yellow River Basin in China, 3S technology can be applied to analysis of regional stability for water conservancy project. Based on water and soil conservation, land use and estuary evolution, we can conduct GPS geographic location positioning, RS map compilation, and the establishment of geographic information model, so as to feedback information on water conservancy project to background management center for analysis and processing. It obtains the synchronous update of land information resources by means of multidimensional dynamic monitoring, and achieves the sharing of environmental information in short period, on 
multi platform, and through multi wave band and multi phase, so as to ensure that various regions can manage the land resources in the Yellow River Basin at the same time synchronously.

3). Evaluation of land resources. At present, evaluation of land resources in our country, completed for a specific purpose under the help of GIS technology, mainly focuses on the production capacity and quality status of land. By means of 3S technology, there are many ways to evaluate the land resources, such as suitability evaluation, potential evaluation, and economic evaluation etc. All of the evaluation work make full use of the openness and theoretical nature of GIS in spatial data management, excavate deeply the potential of land resources, set level for land resources and reveal the quantitative characteristics of land in the law of spatial variation. The release system of land price information also exist in the evaluation system of land resources and its main function is to promote the government's real time management of regional land prices, and also to protect the public's right to know the land price. As a result, both the reasonability and objectivity of the land price have been improved, and it's more conducive to the government's scientific decision-making in land development and transparency of national consumption in the real estate transaction [2].

\section{The future development trends and prospects for application of 35 technology in land resource management in the future}

To ensure the sustainable development of land resources management, we must firstly make reasonable use of the limited land resources and develop 3S technology with efforts so as to dig deeply the effectiveness and diversity of land resource management.

Improve the accuracy of data information in 3S Technology. Nowadays, RS technology of 3S technology in the dynamic monitoring of land resources mainly includes two kinds of images-SPOT and TM, and their resolution is as high as $1 \mathrm{~m}$. However, the technology level of the sensor has a lot of room for improvement. For instance, the integration of the two technologies--RS and GPS can make the management of land location management more accurate, and even meet the mapping requirements of 1:500000. In addition, software for the geographic information system and graphics and image processing software with the functions of man-machine interaction and friendly interface of dialogue are the orientation for development in the future and their common development goals are improving efficiently the accuracy of information in land management.

The modernization for resource management of land information system. As for the modernization for resource management of land information system, the advancement of 3S technology is in high demand. For instance, the application of temporal GIS and visual dynamic management complete the expansion of topological properties, and strengthen the management process of investigation, approval, registration and certification in land management. In such technological state of development, land resources system can offer inquiry, statistics and historical records for land resource system at any time, and realize the function of dynamic tracking for data of land information. Such tracked data would be released on the column of land information on the Internet, so that the land bureau is convenient to conduct electronic business on land transactions and carry out network management plan for distributed land resource [3].

\section{Summary}

In 2015, investigation on land resources was carried out under the background of "Tenth Five Year Plan" and 3S technology became the main topic of high technology once again. Our country hopes that the 3S technology can give full play to its advantages in national land resources and apply the 3S technology reasonably and efficiently land resource management system in the construction of "Digital Land", so as to realize the maximum benefit on national land and the society. 


\section{Reference}

[1] Song Yongjun, Liu Baodong. Current situation and Trend for the Application of "3S" Technology in Land Resource Management. Shandong Land \& Resources, 2005,21 (9): 49-51.

[2] Zha Xianjie, Xing Lixin. Review for the Application "3S" Technology in Land Resources Management. Global Geology, 2000,19 (4): 402-407.

[3] Su Linyuan. Study on the Application of 3S Technology in Land Renewal Investigation. Kunming University of Science and Technology, 2008,34-49. 